\title{
Teachers' Beliefs and Practices of Cooperative Group Work Assessment: Selected Secondary School Teachers in Focus
}

\author{
Abate Demissie Gedamu $^{1}$ Getu Lema Shewangezaw ${ }^{2}$ \\ 1.Department of English language and Literature, Arbaminch University \\ P.o.box 021, Arba Minch, Ethiopia \\ 2.Department of Geography and Environmental Studies, Arbaminch University
}

\begin{abstract}
Group work assessment is still a hot issue which is not yet resolved. This study was to investigate secondary school teachers' beliefs and practices of cooperative group work assessment. In view of this, 213 teachers were selected randomly for questionnaire survey. Besides, two teachers and five students were also selected at each study site for interviews and focus group discussion (FGD), respectively. In order to analyze the data acquired through questionnaire, one-sample t-test was applied. To examine the relationship between teachers' beliefs and practices of cooperative group work assessment, Pearson product moment correlation was used. To analyze data obtained through interview and FGD, qualitative verbal descriptions were employed. The findings showed teachers' had favorable beliefs towards cooperative group work assessment. To the contrary, the assessment practices of group work were partial with focus on group product, with diminutive or no assessment of group process and individual contribution to the group work. From the results of this study, it has been recommended that concerned Education Bureaus have to organize on job training for teachers on cooperative group work in general and assessment of group work in particular.
\end{abstract}

Keywords: belief, practice, assessment, group work, assessment belief, assessment practice

DOI: $10.7176 /$ RHSS/10-7-03

Publication date: April $30^{\text {th }} 2020$

\section{Introduction}

Cooperative learning (CL) is a student-centered teaching and learning pedagogy where students collaborate, communicate and work together on a task in small groups to make best use of their own learning (Johnson \& Johnson, 1999; Sharan, 1994). Literatures disclosed that learners can get multiple benefits from cooperative learning. Accordingly, cooperative learning enhances student performance; interaction, higher self-esteem, problem solving skills and socialization (Johnson \& Johnson, 2002; Slavin, 1996). In addition, it provides nonthreatening, more comfortable and supportive learning environment for students as compared to individual or competitive group works (Gupta, 2004). To be beneficiary from cooperative learning; however, group facilitation roles of teachers have no substitution (Johnson \& Johnson, 1999).

Among the multiple roles teachers are supposed to play, the assessment of cooperative learning is central since it can influence quality learning (Casal, 2016; Gillies \& Boyle, 2010), contents and methods of learning (Biggs, 2002). Concerning cooperative learning assessment practices, the available empirical works have been consulted. To begin with, Le, Janssen and Wubbels (2018) conducted a study on students' and teachers' perceived obstacles to effective collaboration. It was a case study which involved twenty-three students and nineteen teachers from different disciplines in Vietnam University. The study employed interviews to both teachers and students. The finding revealed the assessment of collaborative learning as antecedent obstacle in the implementation of cooperative learning. Hence, the result showed teachers dominantly focused on the assessment of group outcomes and gained knowledge of individuals although some teachers used to assess the collaborative process. This shows that teachers give less emphasis to the assessment of group process. Similarly, Ross, Rolheiser and HogaboamGray (1998) carried a case study on the assessment practices of exemplary users of cooperative learning methods. The finding divulged the participants felt they did not assess often enough, and unable to balance individual and group accountability in their assessment. As the result, they felt their assessments were inaccurate and muddled, careless and practiced inexperienced methods.

In addition, Gillies and Boyle (2010) conducted interviews with ten teachers in two schools on their perceived assessment practices. The finding indicated that they utilized more of informal assessments than that of the formal at large. More specifically, the teachers reported that they took anecdotal evidences going around groups and observed who was active in the task, and who was proceeding correctly in the groups. Besides, the teachers reported that they assessed their students using group discussions and presentations of their works followed by an individual assessment. Furthermore, they pointed that they assessed their students via self-assessment modes. On the same vein, Le, Janssen and Wubbels (2018), revealed that teachers employed group based report, diary, peerand self-assessments. It was reported that teachers used informal assessment of monitoring by going around, and observed their interactions on the tasks. The authors suggested that the involvement of students in the assessment process via peer- and self-assessments coupled with teacher assessment would reduce social loafing (Ross, 
Rolheiser \& Hogaboam-Gray, 1998). On top of this, it was proposed that teachers have to engage students in setting assessment criteria, transparent on what will be assessed and what will be done, and make the scoring key and interpretive schemes visible to students to ensure fairness and acceptability (McInnis \& Devlin, 2002).

Going by the above opinion, assessment for learning should reflect and encourage both individual and group accountability. Strengthening this, a meta-analysis of seventy-seven studies in which CL was compared to the control group (Slavin, 1995 as cited in Ross \& Rolheiser, 2003). The result revealed that CL treatments that included both individual and group accountability had medium effects $(E S=0.32)$ on learning while those that lacked one or more of the elements had negligible impacts ( $\mathrm{ES}=0.07$ to 0.16 ). On the same line of discussion, Barkley, Cross and Howell-Major (2004) note:

Individual grades provide a mechanism to ensure individual accountability but they may minimize the importance of the group effort. Group grades ensure that the group is held accountable and that members support each other's learning, but if individuals are not held accountable, group grades create opportunities for 'easy riders' to avoid responsibility' (p. 83).

The findings and the block quote implied that assessment of cooperative group work should balance individual and group accountability to optimize learning.

In relation to cooperative group work assessment methods (tools), Gillies and Boyle (2010) disclosed that teachers use more of informal than formal assessments methods at large, anecdotal evidences going around, groups, observation, discussions, presentations, individual assessments and self-assessment techniques. Likewise, Le, Janssen and Wubbels (2018) indicated teachers employed group based report, diary, peer- and self-assessments, informal assessment of going around, and observation as tools to assess group work. On the same issue of concern, Jaques (2000) suggested the use of different assessment techniques like shared group grade, project work, exam and oral assessments, peer assessment, and feedback on individual contribution to the group work as useful techniques in cooperative group work assessment. The author further noted the use of various assessment methods would moderate the group mark to the entire group in cooperative group work assessment.

The other issue is teachers' beliefs of group work assessment. Teachers' beliefs, according to Borg (1999), have great potential in influencing the classroom instructional decisions of teachers. To this end, teachers' beliefs of cooperative group work assessment determine the assessment practices of the teachers (Casal, 2016; Rio, 1996). Teachers' beliefs towards the assessment of cooperative group work could influence the actual assessment practices, and hence very important to study it. In this regard, Ross, Rolheiser and Hogaboam-Gray (1998) did a qualitative case study on teachers' beliefs towards the assessment of cooperative learning using interview as tool. The result showed teachers had beliefs that rigorous assessment influenced their' insights and strong views that often characterize CL. Consequently, they felt that recommended assessment strategies of CL conflicted with other goals they held important. They further pin pointed peer-assessment, for instance, would collapse the teambuilding tenet of CL. Therefore, they viewed assessment distinct from and less important than teaching, and loosely linked with teaching.

Thus the association between teachers' beliefs and practices of cooperative group work assessment is paramount important. However, there is scarcity of study on the association between the two variables. This left void may trigger any to examine the relationship between teachers' beliefs and practices of cooperative group work assessment.

The studies conducted on the assessment of cooperative group work are limited. Some of them, (Le, Janssen \&Wubbels, 2018; Gillies \& Boyle, 2010; Ross, Rolheiser \& Hogaboam-Gray, 1998) adopted qualitative case study designs. In addition, they employed only interviews as data collection tool and saw the issue either from teachers or students perspectives as stakeholders in the study. Besides, the result obtained through single tool may not be trustworthy. Therefore, their findings may not be generalized. The study conducted by Slavin (1995), as cited in Ross and Rolheiser (2003), was experimental in its design. It was intended to compare the effectiveness of CL with respect to individual and group accountability with the counter control group in which individual or group accountability or both was removed. Hence, its finding may not show the exhibited actual assessment practices cooperative group work. Consequently, from thesis literatures, it is evident that the association between teachers' beliefs and practices of group work assessment seems a left void or rarely studied.

Taking all these facets into consideration and bearing the potential effects of assessment on learning in general, and the influence of cooperative group work assessment on learning in particular, it appeared very essential to survey teachers' beliefs and practices of cooperative group work assessment using teachers in some selected secondary schools in SNNPRS, Ethiopia. Unless study be warranted on this problem and come up with clear picture of the reality, it would be difficult to take informed remedial intervention if need be.

Specifically, this study sought to meet four specific objectives which include: (i) to explore teachers' beliefs of cooperative group work assessment; (ii) to examine teachers' practices of cooperative group work assessment in terms of assessment of group process, assessors involved in the assessment, and assessment of group product; (iii) to investigate methods (techniques) teachers employed in the assessment of cooperative group work, and (iv) to scrutinize the association between teachers' beliefs and practices of cooperative group work assessment. 


\section{Research Methodology}

\subsection{Research Design}

The objective of the study was to explore teachers' beliefs and practices of cooperative group work assessment in some selected secondary schools in SNNPRS, Ethiopia. To address the objective of the study, a mixed methods design of concurrent/convergent type was adopted. Mixed methods design combines the use of both qualitative and quantitative data in a single study or series of studies. The use of both qualitative and quantitative data in combination in a single study provides a better understanding of research problem than either approach alone. Therefore, employing multiple approaches to social inquiry can provide best understanding of the research problem being investigated, and improve the validity and credibility of the results than the use of a single approach (Saldana, 2011).

Accordingly, quantitative approach was used to generate data through questionnaire from the study participants on teachers' beliefs and practices of cooperative group work assessment. In contrast, semi-structured interview and focus group discussion were employed to collect in-depth data from participants on their beliefs and practice of cooperative group work assessment.

Among the various mixed methods design, this study adopted concurrent/convergent design. This design enhances to get different but complementary data at the same time through questionnaire, semi-structured interview, and focus group discussion on the problem under the study. To this effect, the information acquired through these tools was integrated to get better insight of the phenomena being studied. In addition, this design provides ways to compare and contrast quantitative statistical results with qualitative findings to get a comprehensive picture of the issue under investigation (Creswell, 2009).

\subsection{Participants and their Characteristics}

The study was conducted with secondary school teachers from five schools in SNNPRS which included Arbaminch Secondary School, Karat Secondary School, Sawula Secondary School, Merab-Abaya Secondary School, and Konso Secondary School. These schools were selected because of their relative proximity to the researchers'. The data was collected between June 2019 and January 2020. Employing simple random sampling technique, 254 secondary school teachers who teach at grades 11 and 12 were selected for questionnaire survey. The teachers were sampled from all subjects taught in the school as per the curricula of the Federal State of Ethiopia. Out of 254 teachers that formed sample size, only 213 appropriately filled and returned the questionnaire. For an in-depth interview, two teachers from each school were selected purposively based on their willingness for the interview. In addition, five students were selected in each school for FGD to generate qualitative data on their teachers' group work assessment practices.

The participants drawn from all 14 disciplines taught at secondary school. The index for the participants with reference to the subject they teach was given as: English language $(n=21)$, physical health education $(n=10)$, Amharic ( $\mathrm{n}=16)$, Mathematics $(\mathrm{n}=19)$, Physics $(\mathrm{n}=15)$, Chemistry $(\mathrm{n}=20)$, Biology $(\mathrm{n}=11)$, Geography $(\mathrm{n}=15)$, History ( $\mathrm{n}=25)$, Civic \& Ethical education $(\mathrm{n}=17)$, ICT $(\mathrm{n}=11)$, Technical Drawing $(\mathrm{n}=6)$, General Business $(\mathrm{n}=12)$, and Economics $(\mathrm{n}=15)$. This population was also categorized by gender giving a total of 190 males and 23 females. As to educational level, 170 had first degrees while 43 had masters' degrees. Pertaining to teaching experiences, 21 of them had 1-2 years experiences while 31 recorded 3 to 5 years experiences. In addition, 53 of them had 610 years services while the rest 108 served for more than 11 years.

\subsection{Data Collection Instruments}

Questionnaire, interviews and FGD were used to collect data from the study participants.

\subsubsection{Teacher Questionnaire}

The purpose of the questionnaire was to obtain accurate quantitative data from teachers concerning their beliefs and practices on cooperative group work assessment. To meet this objective, close ended questionnaire was developed on the basis of empirical works (Gillies \& Boyle, 2010; Le, Janssen \& Wubbels, 2018) and related review literatures on cooperative learning (Frykedal \& Chiriac, 2011; Paul \& Ralph, 2005; Valente, 2018; Webb, 1994). The questionnaire constituted of 31 items with two scales. The cooperative group work assessment practice scale had $(n=15)$ items while the cooperative group work assessment beliefs scale consisted of $(n=16)$ items. The questionnaire has two parts. The first part consisted of items that were related to demographic information about the participants' sex, teaching experience, subject they teach, and educational level. The second part focused on teachers' beliefs and practices of cooperative group work assessment on 5-pont Likert scale which included $1=$ strongly disagree, $2=$ disagree, $3=$ undecided, $4=$ agree, and $5=$ strongly agree scales.

The questionnaire was validated for its face validity, content validity, construct validity, and internal consistency reliability before using it for actual data collection. The result indicated a face validity index of $\geq 0.92$ which shows the instrument has acceptable face validity. Concerning content validity of items of the tool, Item Content Validity Index (I-CVIs) for clarity, relevance, and appropriateness were found between acceptable content validity of $0.80-1.00$. Similarly, the Content Validity Index for scale (S-CVI/Ave) was revealed to be 0.91 , which 
is $\geq 0.90$ cut-off value. This entails the tool is content valid at an item and scale levels (Abate \& Getu, 2020; unpublished manuscript).

Concerning construct validity of the tool, principal component analysis (PCA) was conducted with orthogonal Varimax rotation. The 15 items on assessment practices of group work comprised four components which are labeled as assessment of group process $(n=7)$, assessors involved $(n=5)$, and assessment of group product $(n=3)$ items. In the same vein, principal component analysis (PCA) on teachers' beliefs of cooperative group work assessment $(\mathrm{n}=16$ items) confirmed all the items of were retained with four factors which included: beliefs about assessors involved $(n=5)$, assessment of group process $(n=6)$, assessment of social skills $(n=3)$, and assessment of group product $(\mathrm{n}=2)$ items (Abate \& Getu, 2020; unpublished manuscript).

The internal consistency reliability of the factors and scales are presented in table with description below.

Table 1 Internal consistency reliability of factors and scales

\begin{tabular}{lcc}
\hline Factors (assessment practices) & No of items (N) & Cronbach alpha \\
F1 (group process) & 7 & .87 \\
F 2 (assessors involved) & 5 & .74 \\
F3 (group product) & 3 & .66 \\
Scale & 15 & .85 \\
Factors (assessment Beliefs) & & .88 \\
F 1 (assessors involved) & 5 & .89 \\
F 2 (group process) & 6 & .80 \\
F 3 (social skills) & 3 & .68 \\
F 4 (group product) & 2 & .92 \\
Scale & 16 & .70 \\
\hline \hline
\end{tabular}

The internal consistency reliability tests were computed with Cronbach's alpha with value of .70 cut off. In this view, the tool was found to be internally consistent to measure teachers' beliefs and practices of cooperative group work assessment at scales levels. However, the internal consistency reliability values were discovered to be $<0.70$ for assessment of group product $(\alpha=.66)$ and beliefs about assessment of group product $(\alpha=.68)$ subscales. The two sub-scales have been maintained as the assessment of group product is essential aspect. Items or scale with marginal alpha values could be retained if deemed important (DeVon et al., 2007).

2.3.2 Interview

In addition to the questionnaire, semi-structured interview questions were used to intensively probe teachers' assessment beliefs and practices of cooperative group work. To this effect, face-to-face individual interview was conducted with each interviewee.

\subsubsection{Focus Group Discussion}

Focus group discussions were used with selected students at each school to get data on their teachers' cooperative group work assessment practices.

\subsection{Method of Data Analysis}

The data collected through questionnaire was encoded into SPSS version 21 for analysis. Average values at items and scale levels were used as unit of analysis. On the contrary, the data collected through semi-structured interview and focus group discussion was coded and categorized for analysis. One sample $t$-test was used to examine teachers' beliefs of cooperative group work assessment. It could determine whether there was statistically significant difference between the observed mean and expected mean (3.00) at both items and scale levels. In the same way, to decide teachers' practices of cooperative group work assessment, and investigate if the observed mean of the methods teachers employed to assess cooperative group work were statistically and significantly different from expected mean (3.00) at both items and scale levels, one sample $t$-test was applied. To investigate if there was relationship between teachers' beliefs and practices of cooperative group work assessment, Pearson product moment correlation was applied.

The data were checked for the assumptions of one sample $t$-test and Pearson product moment to avoid possible flaws that might have originated from violation of the assumptions of the tools. In addition, five percent $(\alpha=0.05)$ level of significance was used throughout the study.

The data collected through interviews and FGD were coded, categorized and analyzed qualitatively through verbal descriptions.

\section{Results}

One of the specific objectives of this study was to explore teachers' beliefs of cooperative group work assessment with references to sub-scales which included group process, social skills, group product, assessors' involved in the assessment, and beliefs at scale level. The other objective was to examine teachers' practices of cooperative group work assessment in terms of assessors involved, assessment of group process and product. The third one was intended to investigate the assessment methods (tools) teachers employed to assess cooperative group work as part 
of assessment practice. The final one was to investigate the association between teachers' beliefs and practices of cooperative group work assessment. The analysis of each objective has been presented below.

\subsection{Teachers' Beliefs towards Group Work Assessment}

This section presents data analysis on teachers' beliefs towards group work assessment in terms of assessors involved in the assessment, beliefs about assessment of group process, group product (outcome) and social skills. 3.1.1 Teaches Beliefs about Assessors involved in the Assessment of Group Work

Sub-section 3.1.1 presents data analysis on teachers' beliefs about assessors involved in the assessment group work. Table 2. One sample t-test results on teachers' beliefs about assessors involved

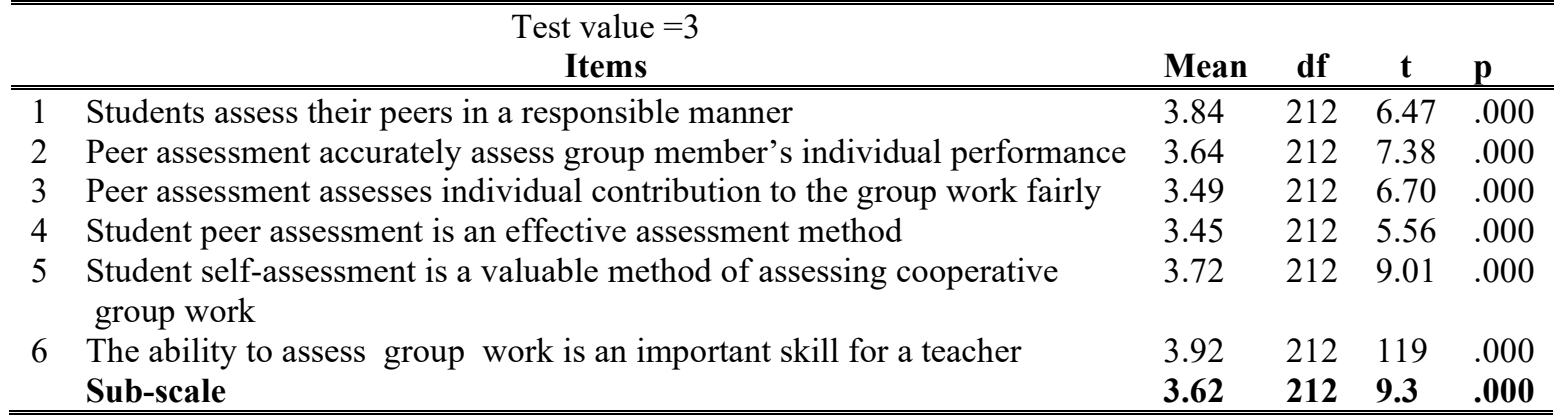

As indicated in table 2 above, the six items of the questionnaire and the sub-scale mean values were found to be statistically significant from the expected mean value of 3.00 at $p<.001$. This implies that teachers had favorable beliefs to the involvement of students in the assessment of group work via peer and self-assessment. They showed that peer assessment is an effective, accurate and fair methods of group work assessment at large and individual contribution to the group work in particular.

3.1.2 Teaches Beliefs about the Assessment of Group Process

Sub-section 3.1.2 presents data analysis on teachers' beliefs about the assessment group work process.

Table 3. One sample t-test results on assessment of group process

\begin{tabular}{|c|c|c|c|c|c|}
\hline & $\begin{array}{c}\text { Test value }=3 \\
\text { Items }\end{array}$ & Mean & df & $\mathbf{t}$ & $\mathbf{p}$ \\
\hline 7 & Assessment of group work plays an important role in fostering learning & 4.08 & 211 & 13.8 & .000 \\
\hline 8 & $\begin{array}{l}\text { Assessment of group work provides feedback to students on their } \\
\text { performances }\end{array}$ & 4.04 & 212 & 15.2 & .000 \\
\hline 9 & Students should take part in assessing their peers in group work & 3.80 & 212 & 11.8 & .000 \\
\hline 10 & The assessment of how students cooperatively worked is important & 4.09 & 212 & 16.2 & .000 \\
\hline \multirow[t]{2}{*}{11} & How students worked on the task (group process) should be assessed & 3.75 & 212 & 10.2 & .000 \\
\hline & Sub-scale & 3.95 & 212 & 16.2 & .000 \\
\hline
\end{tabular}

Similarly, table 3 above indicated the five items on beliefs about the assessment of group process and the subscale mean values were statistically significant from the expected mean value of 3.00 at $p<.001$. This entails that teachers had favorable beliefs on the assessment of group process including the assessment of collaborative skills and performances through peers assessment and feedback for the betterment of learning.

3.1.3 Teaches Beliefs about the Assessment of Social Skills

Sub-section 3.1.3 presents data analysis on teachers' beliefs about the assessment of social skills.

Table 4. One sample t-test results on assessment of social skills

\begin{tabular}{|c|c|c|c|c|c|}
\hline \multicolumn{2}{|r|}{ Test value $=3$} & \multirow{2}{*}{$\frac{\text { Mean }}{4.42}$} & \multirow{2}{*}{$\frac{\mathbf{d f}}{211}$} & \multirow{2}{*}{$\frac{t}{26.5}$} & \multirow{2}{*}{$\frac{\mathbf{p}}{.000}$} \\
\hline 12 & $\begin{array}{l}\text { Feedback on the assessed group tasks helps students to improve their } \\
\text { learning }\end{array}$ & & & & \\
\hline 13 & $\begin{array}{l}\text { Social skills among students should be monitored to develop collaborative } \\
\text { behavior }\end{array}$ & 4.22 & 212 & 21.7 & .000 \\
\hline 14 & The assessment of group work should include assessment of social skills & 3.99 & 212 & 16.7 & .000 \\
\hline & Sub-scale & 4.21 & 212 & 19.4 & .000 \\
\hline
\end{tabular}

As shown in table 4, the items on beliefs about the assessment of social skills and the sub-scale mean values were statistically significant from the expected mean value of 3.00 at $\mathrm{p}<.001$. This shows that teachers had helpful beliefs towards inclusion of social skills and feedback as means to foster social skills of students in addition to cognitive development.

3.1.4 Teaches Beliefs about the Assessment of Group Product

Sub-section 3.1.4 presents data analysis on teachers' beliefs about the assessment of group work product (outcome). 
Table 5. One sample t-test results on assessment of group product

\begin{tabular}{|c|c|c|c|c|c|}
\hline & $\begin{array}{c}\text { Test value }=3 \\
\text { Items }\end{array}$ & Mean & df & $\mathbf{t}$ & p \\
\hline 15 & The assessment of final group work (group product) is important & 4.05 & 211 & 15.2 & .000 \\
\hline 16 & The final group work (group product) should be assessed & 4.15 & 212 & 18.9 & .000 \\
\hline & Sub-scale & 4.09 & 212 & 19.4 & .000 \\
\hline
\end{tabular}

Table 5 indicated the items on beliefs about the assessment of group product and the sub-scale mean values were found statistically significant from the expected mean value of 3.00 at $p<.001$. This shows that teachers had positive beliefs towards the importance of the assessment of group product and its assessment.

\subsection{Teachers' Practices of Group Work Assessment}

This section presents data analysis on teachers' assessment of group work in terms of, assessment of group process, assessors involved in the assessment and assessment of group product (outcome).

3.2.1 Assessment of Group Process

Sub-section 3.2.1 presents data analysis on teachers' assessment of group work process.

Table 6. One sample t-test results on the assessment of group process

Test value $=3$

\begin{tabular}{|c|c|c|c|c|c|}
\hline & Items & Mean & df & $\mathbf{t}$ & p \\
\hline 1 & I frequently check the contribution of each group members to the group work & 3.50 & 212 & 6.82 & .000 \\
\hline 2 & $\begin{array}{l}\text { I give relevant feedback timely on an individual contribution to the } \\
\text { group work }\end{array}$ & 3.59 & 212 & 7.18 & .000 \\
\hline 3 & I give relevant feedback timely on the performance of group work & 3.71 & 212 & 10.23 & .000 \\
\hline 4 & $\begin{array}{l}\text { I use peer assessments to assess the contribution of each member to the } \\
\text { group work }\end{array}$ & 3.32 & 212 & 4.55 & .000 \\
\hline 5 & $\begin{array}{l}\text { I regularly monitor if group members listen each other attentively } \\
\text { to understand each other as they carry out group work }\end{array}$ & 3.62 & 212 & 8.08 & .000 \\
\hline 6 & $\begin{array}{l}\text { I oversee the respect each group member gives to others' opinions and } \\
\text { feelings in the group as they carry out group work }\end{array}$ & 3.74 & 212 & 9.69 & .000 \\
\hline 7 & $\begin{array}{l}\text { I request group members to report the communications they had between } \\
\text { them, } \\
\text { the ideas, strategies, tools and/or resources they used to carry out the activity }\end{array}$ & 3.60 & 212 & 7.89 & .000 \\
\hline & Sub-scale & 3.58 & 212 & 10.34 & .000 \\
\hline
\end{tabular}

As indicated in table 6 above, all the items of the questionnaire and the sub-scale mean values were found to be statistically significant from the expected mean value of 3.00 at $\mathrm{p}<.001$. Accordingly, teachers used to assess group process through peer assessment and provide timely and relevant feedback. In addition, they used to monitor and check the respect they pay each other in their communication as means to cultivate their social skills. Therefore, the data indicated teachers assess both social skills and cognitive performances of the students in group work.

3.2.2 Assessors Involved in the Assessment of Group Work

Sub-section 3.2.2 presents data analysis on assessors involved in assessment.

Table 7. One sample t-test results on assessors involved in assessment

Test value $=3$

\begin{tabular}{|c|c|c|c|c|c|}
\hline & Items & Mean & df & $\mathbf{t}$ & p \\
\hline 8 & I involve students in suggesting assessment tasks for group work & 3.97 & 211 & 17.1 & 1.000 \\
\hline 9 & $\begin{array}{l}\text { I involve students in preparing assessment criteria (scoring rubrics) of group } \\
\text { work }\end{array}$ & 3.38 & 212 & 6.30 & .000 \\
\hline 10 & I use student self-assessments in assessing cooperative group work & 3.60 & 212 & 8.19 & .000 \\
\hline 11 & $\begin{array}{l}\text { I use student peer assessments in my assessment for learning in cooperative } \\
\text { group work }\end{array}$ & 3.39 & 212 & 5.00 & .000 \\
\hline \multirow[t]{2}{*}{12} & I ask the support / feedback each group member gave to other group members & 3.70 & 212 & 11.4 & .000 \\
\hline & Sub-scale & 3.61 & 212 & 13.0 & .000 \\
\hline
\end{tabular}

Table 7 showed that all the items of the questionnaire and the sub-scale mean values were found to be statistically significant from the expected mean value of 3.00 at $p<.001$. The result implied that teachers involved students in the assessment of their own learning through the preparation of assessment rubrics, self and peerassessment.

3.2.3 Assessment of Group Product

Sub-section 3.2.3 presents data analysis on assessment of group work product (outcome). 
Table 8. One sample t-test results on assessment of group product

Test value $=3$

\begin{tabular}{llcccc}
\hline \hline & \multicolumn{1}{c}{ Items } & Mean & df & t & p \\
\hline \hline 13 & I use only my assessments in assessing cooperative group work & 3.12 & 211 & 1.68 & .093 \\
14 & I give each member same mark regardless of the quality of work done by & 3.49 & 212 & 6.31 & .000 \\
& & & & \\
& each member & 3.53 & 212 & 6.36 & .000 \\
& I assess the final group outcome than group work processes & 3.38 & 212 & 6.29 & .000 \\
\hline & Sub-scale & &
\end{tabular}

Table 8 depicted two of the items and the sub-scale mean values on the assessment of group product were found to be statistically significant from the expected mean value of 3.00 at $p<.001$. However, teachers showed ambivalence on whether they use only their assessments alone or not in the assessment of group product. The results showed that teachers assess the group out come and offer the same marks to all regardless of individual contributions to the group work and group process. In other words, the teachers seem to favor the assessment of group product than the process.

\subsection{Assessment Methods (Tools) Teachers Use to Assess Group Work}

Section 3.3 presents data analysis on assessment tools teachers employed in the assessment of group work.

Table 9. One sample t-test results on assessment tools used to assess group work

Test value $=3$

\begin{tabular}{lllllc}
\hline \hline & \multicolumn{1}{c}{ Items } & Mean & df & t & p \\
\hline \hline 1 & Student self-assessments & 3.46 & 212 & 6.77 & .000 \\
2 & Peer assessments & 3.20 & 212 & 2.76 & .000 \\
3 & Teacher assessments & 3.92 & 212 & 12.32 & .000 \\
4 & Teacher Observations/monitors by going around while group work & 3.76 & 212 & 11.16 & .000 \\
& on task & & & & \\
5 & Teacher Observations with observation check lists & 3.55 & 212 & 7.28 & .000 \\
6 & Paper and pencil works (tests, quizzes, examinations) & 4.02 & 212 & 12.23 & .000 \\
7 & Group written reports after students worked together & 3.27 & 212 & 3.89 & .000 \\
8 & Individual written reports after students worked together & 2.90 & 212 & -1.19 & .233 \\
9 & Individual reflective diary & 2.58 & 212 & -5.12 & .000 \\
10 & Group presentations & 3.32 & 212 & 4.69 & .000 \\
11 & Individual presentations & 2.89 & 212 & -1.35 & .178 \\
12 & Group discussions & 3.93 & 212 & 13.63 & .000 \\
13 & Portfolio assessments & 2.51 & 212 & -5.37 & .000 \\
14 & Interviews on work done in group & 2.26 & 212 & -10.2 & .000 \\
15 & Project works & 2.48 & 212 & -5.65 & .000 \\
16 & Demonstrations & 2.12 & 212 & -11.7 & .000 \\
17 & Experiments & 1.71 & 212 & -25.0 & .000 \\
18 & Debates & 1.82 & 212 & -22.4 & .000 \\
& Scale & $\mathbf{2 . 9 8}$ & $\mathbf{2 1 2}$ & $\mathbf{- . 3 7}$ & $\mathbf{. 7 1 5}$ \\
\hline \hline
\end{tabular}

Table 9 showed statistically significant higher observed mean values from the expected mean of 3.00 at $\mathrm{p}<.001$ for items numbered from $1-7$ and items $10 \& 12$. Conversely, statistically significant but lower mean values from the expected mean of 3.00 at $p<.001$ were obtained for item 9 and items 13-18. In addition, statistically non-significant mean differences were found between observed and expected means for items of number $8 \& 11$ at $\mathrm{p}>0.05$. The result revealed that teachers claimed they apply peer and self-assessment, teacher assessment, monitoring, observations, traditional paper-pencil tests, written group works, group presentations and group discussions as assessment tools in the assessment of group work. On the contrary, teachers rarely use other assessment tools (item 9, and 13-18 items) in their assessment of group work. However, the teachers left undecided on the use of individual written reports and individual presentations.

\subsection{Relationship between Teachers' Beliefs and Practices of Group Work Assessment}

Section 3.4 presents the association between teachers' beliefs and practices of group work assessment. 
Table 10 Pearson Product-Moment Correlations Between Measures of Assessment Beliefs and Practices

\begin{tabular}{|c|c|c|c|c|c|c|c|c|}
\hline Measures & 1 & 2 & 3 & 4 & 5 & 6 & 7 & 8 \\
\hline 1 BAI & -- & & & & & & & \\
\hline 2 BAGP & $.605 * *$ & --- & & & & & & \\
\hline 3 BASS & $.426 * *$ & $.614^{* *}$ & --- & & & & & \\
\hline 4 BAGPT & $.611 * *$ & $.586^{* *}$ & $.437 * *$ & --- & & & & \\
\hline 5 TAB & $.832 * *$ & $.864 * *$ & $.736^{* *}$ & $.815^{* *}$ & --- & & & \\
\hline 6 AGP & $.302 * *$ & $.327 * *$ & $.312 * *$ & $.222 * *$ & $.357^{*}$ & --- & & \\
\hline 7 AIA & $.256 * *$ & $.370 * *$ & $.323 * *$ & $.137 *$ & $.331 * *$ & $.596 * *$ & --- & \\
\hline 8 AGPT & $.281 * *$ & $.264 * *$ & $.296^{* *}$ & $.210^{* *}$ & $.327 * *$ & .082 & $.195 * *$ & --- \\
\hline 9 TAP & $.303 * *$ & $.306^{* *}$ & $.327 * *$ & $.226^{* *}$ & $.355 * *$ & $.136^{*}$ & $.305^{* *}$ & $.987 * *$ \\
\hline
\end{tabular}

$\mathrm{BAI}=$ beliefs about assessors involved, $\mathrm{BAGP}=$ beliefs about assessment of group process, $\mathrm{BASS}=$ beliefs about assessment of social skills, BAGPT $=$ beliefs about assessment of group product, $\mathrm{TAB}=$ total assessment beliefs, AGP= assessment of group process, AIA= assessors involved in assessment, $\mathrm{AGPT}=$ assessment of group product, $\mathrm{TAP}=$ total assessment practice

Before running Pearson product-moment correlation for examining the association between teachers' beliefs and practices of cooperative group work assessment, preliminary analyses were performed and the results insured there were no violation of the assumptions of normality, linearity and homoscedasticity. The Pearson productmoment correlation result showed positive and significant medium correlation $(\mathrm{r}=.355, \mathrm{~N}=213, \mathrm{p}<.001)$ between beliefs and practices of cooperative group work assessment scales. Besides, statistically significant, but small and medium correlations were obtained between beliefs and practices sub-scales of the two scales. This implied that the stronger the beliefs the teachers held on the assessment of cooperative group work, the more they may assess cooperative group work.

\subsection{Interview Data Analysis}

Under this section, interview data from teachers on their beliefs and practices of group work assessment has been analyzed. Besides, students' perspectives of their teachers' group work assessment practices have been analyzed. Each has been presented in the following two sub-sections.

3.5.1 Teachers' Beliefs and Practices of Group Work Assessment

Pertaining to the beliefs teachers had on the assessment of group work, they began their reflection from the general beliefs on cooperative learning and went specific to their beliefs on the assessment of group work. In view of this, they reported that cooperative group work is a useful pedagogy which enhances to pull up struggling learners from where they have been while at the same time enriches the skills and knowledge of the advanced and grade level learners as well. However, some teachers believe that group work is a top-down imposition including its assessment.

Conversely, teachers had also favorable beliefs towards cooperative group work and its assessment. They believe that cooperative group work and its assessment are very important. One of the interviewed teachers noted: I have been using cooperative group work as much as I could. As the assessment of cooperative group work is inseparable from the implementation of group work, I also have firm beliefs on the necessity of group work assessment. Unless we develop strong ground on the importance of cooperative group assessment, we may not attempt the assessment (Teacher 2).

The result of interview data presented earlier on teachers' beliefs on cooperative learning in general and group work assessment in particular are contradictory. Due to this difference, one interviewed teacher suggested some sort of consensus to be maintained on cooperative learning in general and group work assessment in particular for its effective implementation (Teacher 4).

It is obvious that the beliefs one held influence practices. Favorable beliefs towards assessment of cooperative group work will have positive effect on the betterment of cooperative group work assessment practices as the two co-exist. Accordingly, teachers' interview on the assessment practices of group work showed they use information from group on an individual contribution to the group work and group process. In addition, the teachers disclosed they used to employ both formal and informal assessment systems. One of the interviewees remarked the assessment of cooperative group work:

I let group leader to facilitate discussions, and monitor the contribution of each member to the group work and the group process. Hence, the group leader will monitor the group process; I assess the group product. In addition, I sometimes go around and monitor for their interactions and contributions to the group work. Moreover, I sometimes question an individual for his/her contribution to the group work on random basis during whole class discussion (Teacher 1).

On the same line of discussion, teacher 4 stated that:

The group leader reports the level of participation and contribution of each member of the group. I grade 
the group work final product and give the same marks to all on the basis of equal participation assumption report of the group leader in addition to my personal attempt to check for individual contribution.

This shows that teachers assess the group product on the basis of the final work without considering group process and individual contribution to the group work although they ask the group leader for report on an individual contribution and group process.

\subsubsection{Students' Views of their Teachers' Group Work Assessment Practices}

Concerning group work assessment practices, focus group discussion results showed teachers inured to assess group work product mostly on the expense of group process. The students reported teachers ask for group leader reports on the contribution of individuals to the group tasks. Yet, the students told they have not seen the teachers marking of individual contribution to the group work. Instead, they reported they experienced equal marks for all in spite of the differences in the individual contribution to the group work. The further pin pointed that the reports from the group leaders were not considered in marking by the teachers.

In contrary to this, the students reported that very few teachers assess group process and offer marks according to our contribution to the group work. Accordingly, the students stated that these teachers used to let the students to rank the contribution of each member as per the contribution and involvement of each in the work. They further noted that the teachers, on the basis of individual contribution ranked by the group members and leader, offered marks according to individual contribution to the group work instead of equal marks to all.

Concerning student involvement in the assessment process, the FGD discussants described some of their teachers rarely let them assess each other on the contributions they made to the group work. They reported the teachers used to involve them rarely via peer assessment modes as means to assess each other on their contribution to the group work. They told that they get marks according to their contribution to the group work in very rare situation.

With regard to the assessment tools teachers use to assess group work, the discussants reported some teachers used informal assessment through going around to observe students while in classroom and in school compound reserved for group work. In addition, the students reported their teachers sometimes used to ask a member of the group question related to the group tasks randomly as means for checking the group process. Besides, few teachers randomly ask someone to present group work instead of group leader. Moreover, it was reported that some teachers do informal assessments and group presentations. However, these might not be enough follow up as these practices were not intensive, frequent, and were not done by all teachers.

\section{Discussion and Conclusions}

The results obtained from questionnaire indicated teachers had favorable beliefs towards cooperative group work assessment. Teachers showed positive beliefs towards the assessment of cognitive and social skills, group products and process, and involvement of students in the assessment of group work. They believe that peer assessment is an effective, accurate and fair method of group work assessment and individual contribution to the group work. Therefore, the teachers took for granted the involvement of students in the assessment through peer and selfassessment. The interview results also disclosed teachers had favorable beliefs towards cooperative group work assessment. This finding is contradictory to the results of an early case study which showed disparity between the teachers' insights and strong views they had about cooperative learning and group work assessment (Ross, Rolheiser \& Hogaboam-Gray, 1998). The duo found that teachers had beliefs that peer-assessment would crumple the team-building principle of cooperative learning.

With regards to the assessment practices of group work, the results gained from questionnaire revealed teachers were insensible to assess group process, group product, and involve students in the assessment. Thus, teachers used to assess group process through peer assessment and provide timely and relevant feedback. Besides, they monitor the respect the students pay each other in their communication as means to cultivate their social skills. However, the teachers seem to favor the assessment of group product than the process. Concerning the student involvement in the assessment of their own learning, teachers claimed they involve students in preparing assessment rubrics, self and peer-assessment. Conversely, the interview and FGD results revealed that teachers dominantly assess the group product with little consideration of the assessment of group process and individual contribution to the group work. Although teachers were accustomed to ask for group leaders' reports on the contribution of individuals to the group work, they used to grade the group final product and offer the same marks to all on the assumption of equal participation with little or no grading the process and individual contribution in most cases. This finding is harmonious with Le, Janssen and Wubbels (2018) who divulged the assessment of teachers were prevailingly centered on group products and gained knowledge of individuals with infrequent assessment of collaborative process. The finding of current study is also congruent with Ross, Rolheiser and Hogaboam-Gray (1998) that teachers fell short of offering copious and adequate assessments that could balance individual and group accountability in their group work assessment practices.

With regard to group work assessment tools, the results attained from questionnaire demonstrated that teachers asserted they applied peer and self-assessment, teacher assessment, monitoring, observations, traditional 
paper-pencil tests, written group reports, group presentations and group discussions as assessment tools. Divergently, the finding evidenced teachers rarely use individual reflective diary, portfolios, interviews, project works, demonstrations, experiments and debates in their assessment of group work. Nevertheless, the teachers left undecided on the use of individual written reports and individual presentations as tools. The interview and FGD results also confirmed that teachers employ more of informal than formal assessment, and use very few of them in spite of the various assessment tools that may be used. This finding is in line with Gillies and Boyle (2010) and Le, Janssen and Wubbels (2018) which showed that teachers use finger counted assessment tools in which most were informal assessment modes.

In connection with the association between teachers' beliefs and practices of cooperative group work assessment, the results unveiled that there are direct and significant positive relationships between beliefs and practices scales and their sub-scales. This shows the more the teachers held positive beliefs towards cooperative group work assessment, the better the possibility of cooperative group work assessments. Nevertheless, the qualitative data results have not showed direct relations between teachers' beliefs and practices of cooperative group work assessment.

Based on the results, it is reasonable to conclude that teachers have promisingly positive beliefs towards cooperative group work assessment. Teachers' favorable beliefs towards cooperative group work assessment could be a fertile ground to effective assessment practices since beliefs have immense opportunities of influencing teachers' classroom instructional decisions including assessment. In spite of teachers positive beliefs towards cooperative group work assessment, their assessment practices of group work were partial with focus on group product, with little or no attention to the assessment of group process and individual contribution to the group work, and less involvement of students in the assessment. In addition, equal marks to all regardless of equal contribution have been found an established feature in the assessment attempt of the teachers. On the overall, teachers' have been limited to few and inadequate assessment tools which are directed by informal assessments.

On the basis of the findings, it will be plausible to forward some recommendation. Concerned bodies have to organize on job training on cooperative group work in general and on the assessment of group work in particular. In addition, teacher education institutions need to consider means to include cooperative group work assessment in their curricula for their graduates at different levels of teachers' certifications.

This study focused on secondary school teachers selected from five schools at SNNPRS in Ethiopia. Further study need to be conducted at different educational levels and localities to generalize the findings. Besides, future studies on similar issue should consider if the participants' sex, educational status, teaching experiences, and fields of study could bring differences on the findings of this study, as these variables were not the concern of the current study.

\section{Acknowledgements}

We would like to acknowledge Arba Minch University for funding this study. We would also like to thank head of research coordination office at CSSH for his genuine and unreserved facilitation of research fund and timely responses to any query we had. We are also grateful to teachers and students who were cooperative and helpful during the data collection. Last but not least, we would like to extend our gratitude to Dr. Tesfaye H. Mariam for his constructive comments.

\section{Conflict of interests}

There is no conflict of interests.

\section{References}

Abate, D. \& Getu, L. (2020). Validation of questionnaire on teachers' beliefs and practices of cooperative group work assessment (unpublished manuscript).

Barkley, E., Cross, P., \& Howell-Major, C. (2004). Collaborative learning techniques: A handbook for college faculty. San Francisco: Jossey-Bass. 288.

Biggs, J. (2002). Teaching for quality learning at university. Society for research into higher education and open University press, Buckingham UK.

Borg, S. (1999). Teachers' theories in grammar teaching. ELT Journal, 53(3), 157-167.

Casal, S. (2016). Cooperative Assessment for Learning in CLIL Contexts. Estudios Sobre Education, 31, 139-157. DOI: $10.15581 / 004.31 .139-157$

Creswell, J. (2009). Research design: Qualitative, quantitative and mixed methods approaches (3rd ed.). Los Angeles: Sage Publications Inc.

Frykedal, K. F., \& Chiriac, E. H. (2011). Assessment of students' learning when working in groups. Educational Research, 53, 331-345.

Gillies, R., \& Boyle, M. (2010). Teachers' reflections on cooperative learning: Issues of implementation. Teaching and Teacher Education, 26, 933-940. 
Gupta, L. (2004). Enhancing student performance through cooperative learning in physical sciences. Assessment and Evaluation in Higher Education, 29, 63-73.

Le, H., Janssen, J., \& Wubbels, T.(2018). Collaborative learning practices: teacher and student perceived obstacles to effective student collaboration, Cambridge Journal of Education, 48(1), 103-122, DOI: 10.1080/0305764X.2016.1259389

Johnson, D., \& Johnson, R. (1999). Making cooperative learning work. Theory Into Practice,38, 67-73.

Johnson, D., \& Johnson, R. (2002). Learning together and alone: overview and meta-analysis. Asia Pacific Journal of Education, 22, 95-105.

Johnson, D., \& Johnson, R. (2008). Social Interdependence Theory and Cooperative Learning: The Teacher's Role. In R. M. Gillies, A. Ashman \& J. Terwel (Eds.), Teacher's Role in Implementing Cooperative Learning in the Classroom (pp. 9-37). New York, U.S.A: Springer. http://dx.doi.org/10.1007/978-0-387-70892-8_1

McInnis, J. R. \& Devlin, M. (2002). Assessing learning in Australian universities. www.cshe.unimelb.edu.au/assessinglearning

Paul, E. K., \& Ralph, R. B. (2005). Problems Associated with Evaluating Student Performance in Groups. College Teaching, 53(2): 57-61. URL: http://www.jstor.org/stable/27559221

Rios, F. (1996). Teacher thinking in cultural contexts. New York: State University of New York Press.

Ross, J., Rolheiser, C. \& Hogaboam-Gray, A. (1998) 'Student evaluation in cooperative learning: teacher cognitions', Teachers and Teaching: Theory and Practice, 4: 299-316.

Ross, J., \& Rolheiser, C. (2003). Student assessment practice in co-operative learning. In R., M. Gillies \& A., F. Ashman (Eds.), Co-operative learning. The social and intellectual outcomes of learning in groups. London: RoutledgeFalmer.

Saldana, J. (2011). Fundamentals of qualitative research: Understanding qualitative research. New York: Oxford University Press, Inc.

Sharan, S. (Ed.). (1994). Handbook of cooperative learning methods. Westport, CN: Greenwood Press.

Slavin, R. (1996). Research on cooperative learning and achievement: What we know, what we need to know. Contemporary Educational Psychology, 21, 43-69.

Valente, L. (2018). CO-LAB Guidelines for Assessing Collaborative Learning in the Classroom. Brussels: European School net. Available at http://colab.eun.org/

Webb, N. M. (1994). Group collaboration in assessment: competing objectives processes and outcomes. Technical Report 386. CRESST/University of California, Los Angeles. 